\title{
DESAIN PANTI SOSIAL TRESNA WERDHA DI MAKASSAR
}

\author{
Burhanuddin 1 , Ratriana Said ${ }^{2}$, Wahdaniar ${ }^{3 *}$ \\ Arsitektur Universitas Islam Negeri Alauddin Makassar, Arsitektur Universitas Islam Negeri \\ Alauddin Makassar, Arsitektur Universitas Islam Negeri Alauddin Makassar \\ e-mail: ${ }^{1}$ amin.burhanuddin@gmail, ${ }^{2}$ ratriana@gmail.com, ${ }^{3 *}$ wahdaniarm@gmail.com
}

\begin{abstract}
Abstrak_ Jumlah lansia di kota Makassar baik yang tergolong terlantar dan hampir terlantar berdasarkan data pemerintah setempat saat ini semakin meningkat. Untuk itu diperlukan perhatian dan penanganan yang serius dari berbagai pihak. Salah satu kebutuhan utama lansia adalah sarana tempat bernaung yakni panti sosial tresna werdha. Permasalahan yang umum pada lansia di daerah perkotaan adalah kemiskinan, ketelantaran, kecacatan, serta tidak adanya sanak saudara yang mendampingi dan memberikan bantuan perekonomian. Tujuan dari desain panti werdha ini ialah sebagai salah satu bentuk solusi untuk menjawab kebutuhan para manusia usia lanjut, yakni selain sebagai tempat hunian, juga mewadahi beberapa fasilitas yang sangat dibutuhkan seperti fasilitas kesehatan yang dapat memantau kesehatan mental dan fisik para lanjut usia mengingat mereka mengalami kemunduran dalam kesehatan juga fasilitas sosial lainnya. Metode yang digunakan dalam pembahasan ini adalah deskriptif kualitatif yang selanjutnya dilakukan eksplorasi dalam bentuk desain grafis sehingga didapatkan visualisasi sebuah panti sosial yang nyaman dan sesuai dengan kebutuhan dan perilaku penghuninya.
\end{abstract}

Kata kunci : Panti Sosial; Tresna Werdha; Lanjut Usia

\begin{abstract}
The number of elderly in the city of Makassar is currently increasing, neither of which belongs to the displaced and almost abandoned. For it, is necessary required serious attention and handling of various parties as a means needs of places workhouses. A common problem in the elderly in urban areas was poverty, abandoned, disability, as well as the absence of relatives who accompany and help the economy. The purpose of The Werdha Parlors is to accommodate the elderly man with providing some of the facilities needed. In addition to residential facilities, also provided other support facilities such as health facilities that monitor the mental and physical health of the elderly considering their decline in health. The methods used in this research: with a descriptive qualitative. From these results then conducted exploration in the form of graphic design so obtained the design of a social parlors are comfortable and appropriate to the needs of its inhabitants.
\end{abstract}

Keywords : Social Homes; Tresna Werdha; Elderly

\footnotetext{
${ }^{1}$ Arsitektur Universitas Islam Negeri Alauddin Makassar

Arsitektur Universitas Islam Negeri Alauddin Makassar

${ }^{3}$ Arsitektur Universitas Islam Negeri Alauddin Makassar
} 


\section{PENDAHULUAN}

Indonesia sebagai negara keempat terbanyak populasi penduduknya di dunia, setelah Cina, India, dan Amerika Serikat, dan terbanyak di wilayah Asia Tenggara dan 10 negara yang tergabung dalam ASEAN. Sudah selayaknya Indonesia Sebagai role model bagi negara tetangganya, terutama dalam penanganan penduduk, khususnya penduduk lanjut usia (lansia). Berdasarkan data proyeksi penduduk, diperkirakan tahun 2015, terdapat 21,68 juta jiwa penduduk lansia di Indonesia (8,49 persen) dari populasi penduduk, hal ini menunjukkan bahwa di Indonesia termasuk negara yang akan memasuki era penduduk menua (ageing population) karena jumlah penduduknya yang akan berusia 60 tahun ke atas (penduduk lansia) melebihi angka 7 persen. Di prediksi jumlah penduduk lansia tahun 2020 (27,08 juta), tahun 2025 (33,69 juta), tahun 2030 (40,95 juta) dan tahun 2035 (48,19 juta). (BPS Sulawesi Selatan, 2015)

Penduduk lanjut usia memerlukan program pelayanan kesejahteraan sosial, guna meningkatkan angka harapan hidupnya melalui program pelayanan kesejahteraan sosial yang terencana, tepat guna dan tetap memiliki karakteristik yang harmonis dalam perlindungan sosial. Hal ini sesuai dengan penjelasan (UUD 1945, pasal 28H, ayat 1, n.d.) bahwa, "Setiap orang berhak hidup sejahtera lahir dan batin, bertempat tinggal, dan mendapatkan lingkungan hidup yang baik dan sehat serta memperoleh pelayanan kesejahteraan". Lanjut usia terlantar berhak memperoleh pelayanan publik melalui unit pelayanan sosial, Provinsi Sulawesi-Selatan sebagai upaya program pelayanan kesejahteraan sosial bagi lanjut usia.

Gambaran mengenai jumlah dan presentasi lansia dari seluruh lansia di Indonesia pada tahun 2015, yaitu sekitar 22,04 juta jiwa terdapat 66,94 persen termaksud kategori lansia tidak terlantar, 23,52 persen termaksud kategori lansia hampir terlantar, dan sisanya 9,55 persen diantaranya termasuk kategori lansia terlantar (Badan Pusat Statistik Sulawesi Selatan, n.d.). Melihat masih banyaknya lansia yang tergolong terlantar dan hampir terlantar di perlukan perhatian dan penanganan yang serius dari berbagai pihak, dalam hal ini tidak saja pemerintah melainkan juga anggota keluarga dan seluruh elemen masyarakat (Badan Pusat Statistik Sulawesi Selatan, n.d.).

Seiring dengan meningkatnya jumlah lansia, turut serta membawa berbagai permasalahan. Permasalahan yang umum pada lansia di daerah perkotaan adalah kemisikinan, ketelantaran, kecacatan, serta tidak adanya sanak saudara yang mendampingi dan memberikan bantuan perekonomian. Menurut (Dinas Sosial Provinsi Sulawesi Selatan pada tahun 2017, n.d.), jumlah lansia terlantar dan tidak memiliki keluarga pada 17 Kabupaten dari 24 Kabupaten di Sulawesi Selatan yaitu sebanyak 450 lansia pada tahun 2010, 580 lansia pada tahun 2011, 1150 tahun 2012-2014, dan 1250 lansia dari tahun pada 2015 sampai dengan tahun 2017. Hal yang demikian ini yang harus diantisipasi dan dicarikan jalan keluarnya. Berdasarkan (Peraturan Daerah Kota Makassar Nomor 31 tahun 2004 pasal 15e, n.d.) bahwa, "Bidang Rehabilitasi dan Pelayanan Sosial menyelenggarakan fungsi penyelenggaraan pelayanan sosial bagi lanjut usia terlantar, anak terlantar, fakir miskin, orang terlantar".

Dengan demikian perlu adanya suatu Panti Werdha di Makassar yang dapat menampung para menula dengan menyediakan beberapa fasilitas yang dibutuhkan. Selain fasilitas hunian, juga disediakan fasilitas pendukung lainnya seperti fasilitas kesehatan yang memantau kesehatan mental dan fisik para lanjut usia mengingat mereka mengalami kemunduran dalam kesehatan. Fasilitas yang bersifat spiritual juga harus disediakan, mengingat mereka dalam usia lanjut ini makin mendekatkan diri pada Tuhan sebagai pencipta mereka.

Menurut (Evian 2016) bahwa "perancangan hunian yang nyaman dan aman bagi lansia adalah hunian yang dapat memberi pengaruh psikologis penghuninya". Oleh karena itu diperlukan pemahaman tentang karakteristik lansia. Sedangkan menurut Fira Yasmin (2016), dalam merancang Panti Werdha konsep interior sangat penting, baik perencanaan tata letak, tata ruang, sirkulasi, desain fasilitas, kapasitas dan pembentukan suasana pada ruang agar memberikan kesan aman dan nyaman bagi lansia saat beraktifitas. Sedangkan menurut (Angelina, Agustina, Widyani Ika, Gatot 2015) bahwa

"menciptakan lingkungan dan bangunan yang berfungsi menjawab persoalan keterbatasan lansia yaitu 
dengan desain yang aman dan sesuai dengan standar dalam segi arsitektural, serta memfasilitasi kebutuhan dan aktivitas lansia dengan memperhatikan aspek perilaku dan lingkungannya".

Dalam hal ini konsep desain yang digunakan dalam perancangan Panti Werdha yaitu mengaitkan antara perilaku dan penggunaan bangunan yang dirancang. Menggunakan pendekatanpendekatan arsitektur perilaku difokuskan pada perancangan ruang bagi lansia yang aman dan sesuai standar dengan memperhatikan kebutuhan dan aktivitasnya dalam segi arsitektural, dan menwujudkan perencanaan lingkungan pada Panti Werdha yang menunjang kebutuhan dan aktivitas lansia, yang tujuannya untuk menciptakan suatu bangunan yang berfungsi menjawab segi arsitektural melalui pendekatan arsitektur perilaku, dan menghasilkan suatu lingkungan dengan perencanaan Panti Wredha yang dapat menunjang dan mempasilitasi kebutuhan serta aktivitas lansia.

\section{METODE}

Metode pembahasan diawali dengan pengumpulan data primer dengan melakukan survey pada Panti Wredha yang telah ada di kota Makassar terlebih dahulu. Selanjutnya diolah melalui analisis dan sintesis data yang kemudian di proses menjadi sebuah konsep perancangan. Pembahasan data primer dilakukan dengan metode deskriktif kualitatif dengan menjelaskan latar belakang kebutuhan fasilitas penunjang, data penduduk lansia dan identifikasi kondisi tapak yang menjadi lokasi perancangan, sedangkan pengumpulan data sekunder diperoleh dari pembelajaran pustaka terkait fungsi panti jompo, studi komprasi fungsi sejenis. Tahap analisis dan sintesis dimulai dengan pengolahan data secara sistematis dan menerapkan metode desain seperti metode pragmatis dan tipologi yang disesuaikan dengan tiap kriteria desain. Konsep perancangan yang telah didapat lalu ditransformasikan ke dalam bentuk desain grafis dengan menggunakan metode eksplorasi desain sehingga dapat memperoleh gambar perancangan yang menerapkan sebuah panti jompo yang nyaman mencakup lokasi, bentuk hunian dan fasilitas penunjang pada panti.

\section{HASIL DAN PEMBAHASAN}

\section{A. Lokasi Perancangan}

Dalam pemilihan lokasi untuk Panti Sosial Tresna Werdha harus sesuai dengan (Peraturan Daerah kota Makassar No. 4 Tahun 2015, n.d.). Sesuai dengan (Rencana Tata Ruang Wilayah (RTRW) Kota Makassar tahun 2015-2034 yaitu Sub Pelayanan Kota, Pasal 20 ayat 2, n.d.) yang berisi tentang Sub PPK VI ditetapkan pada kawasan losari yang mencakup kecamatan Mariso, Kecamatan Ujung Pandang, dan Kecamatan Wajo dengan fungsi sebagai pusat kegiatan perumahan kepadatan sedang, pusat kegiatan perumahan kepadatan tinnggi, pusat kegiatan perdagangan dan jasa, pusat kegiatan pariwisata, pusat kegiatan sosial budaya, pusat pelayanan kesehatan, dan pusat kegiatan transportasi laut. 


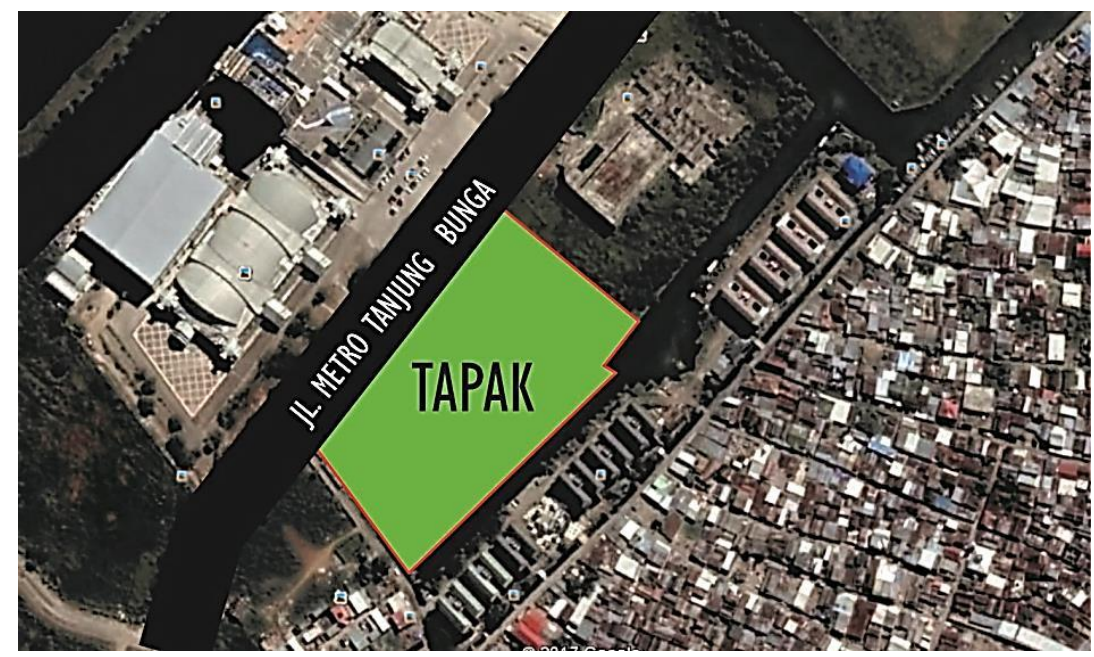

Gambar 1. Lokasi Kawasan

Sumber: Olah Desain, 2018

Tapak perencanaan dan perancangan bangunan Panti Sosial Tresna Werdha terletak di jalan Metro Tanjung Bunga, Kelurahan Panambungan, Kecematan Mariso, Kota Makassar, Provinsi Sulawesi Selatan (Gambar 1). Keadaan tapak/site sangat mendukung dengan luas tapak pada perancangan Panti Sosial Tresna Werdha \pm 2.8 Ha. Luasan harus mencakup dalam perancangan beberapa fasilitas pendukung pada Panti Sosial Tresna Werdha.

Akses menuju tapak dapat dilalui dua jalan yaitu jalan Metro Tanjung Bunga dan jalan Nuri Lorong 300 yang memiliki tingkat kebisingan cukup tinggi yang di sebabkan karena padatnya kendaraan yang melalui jalan tersebut. Sedangkan untuk fasilitas dan utilitas pada tapak cukup terjangkau yaitu dengan tersedianya jaringan air bersih dari perusahaan daerah air minum (PDAM), jaringan listrik dari PLN, jaringan pembuangan sampah dari dinas kebersihan kota Makassar dan jalur drainase.

\section{B. Konsep Bentuk, Struktur dan Material Bangunan}

Penentuan bentuk dan penampilan bangunan Panti Sosial Tresna Werdha ini, didasarkan pada pertimbangan fungsi, ekspresi budaya, dan penyesuaian terhadap potensi dan keadaan lingkungan sekitar tapak. Filosofi bentuk merupakan elemen penting dalam mewujudkan ekspresi bangunan, dimana pendekatannya bertumpu pada pemaknaan nilai-nilai yang akan dimunculkan pada Panti Sosial Tresna Werdha.

Bentuk dasar bangunan hunian pada Panti Sosial Tresna Werdha diaplikasikan dari filosofi lansia yang sedang bungkuk dan menggunakan tongkat (Gambar .2), sedangkan bentuk bangunan fasilitas penunjang diambil dari rumah panggung Bugis-Makassar yang mempunyai filososfi sifat bangunan yang bermakna hangat, humble, nyaman (comfortable), dan tenang. Hal ini juga terlihat dari kesan yang ditimbulkan dalam pemilihan material, warna dan bentuk bangunan pada rumah adat Bugis-Makassar (Gambar.3). Selain itu filosofi fisik bangunan rumah adat Bugis-Makassar yaitu kepala, badan, dan kaki juga diaplikasikan pada bangunan-bangunan yang berada pada panti ini. Konsep filosofi bentuk didasarkan pada pertimbangan : (1) kesesuaian bentuk dengan kondisi tapak, (2) kesesuaian bentuk dengan fungsi bangunan serta kegiatan yang akan diwadahi, (3) Efektifitas ruang serta kemudahan dalam pelaksanaan, (4) kesan bentuk dan penampilan serta keserasian bentuk dengan lingkungannya. 


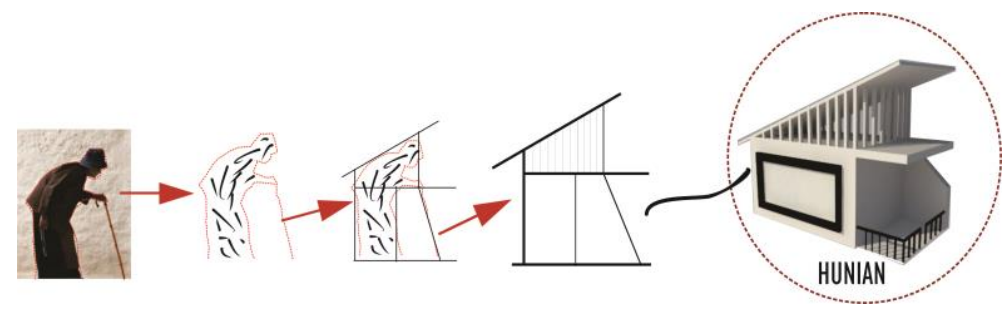

Gambar 2. Transformasi Bentuk Bangungan Hunian Sumber ; Hasil Dsain, 2018

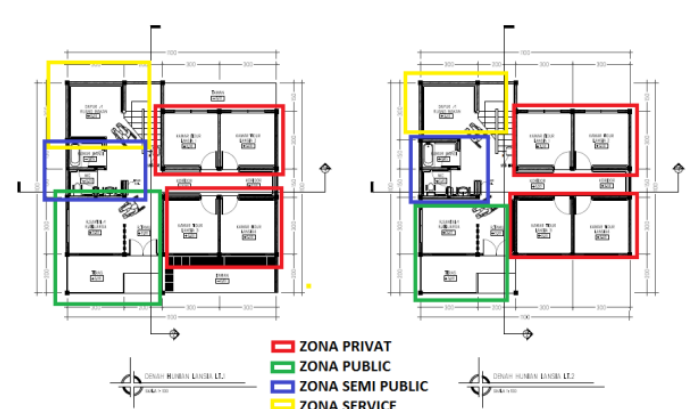

(a)

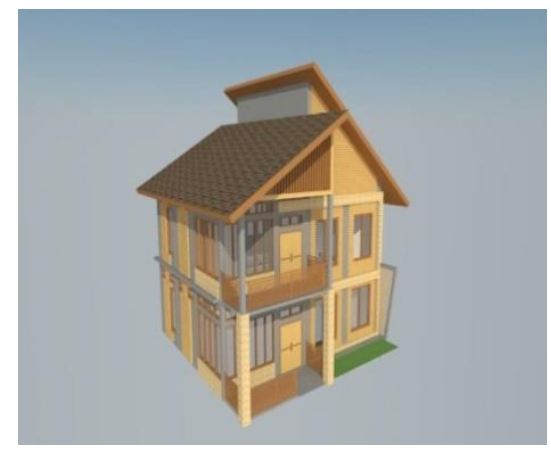

(b)

Gambar 3. Kondisi Ide Desain Hunian Lansia

Sumber ; Hasil Dsain, 2018

Adapun rencana jumlah hunian lansia pada Panti Sosial Tresna Werdha yaitu sebanyak 15 hunian dengan setiap huniannya terdiri dari dua lantai yang dapat dihuni hingga 8 orang lansia.

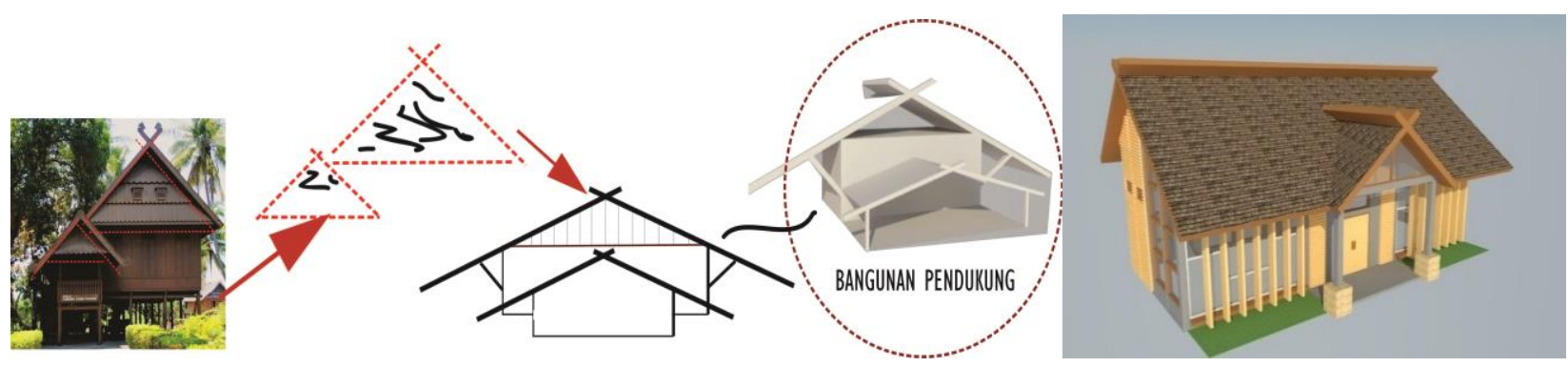

Gambar 4. Transformasi Bentuk Bangungan Penunjang Sumber: Hasil Desain, 2018

Kebutuhan bangunan penunjang pada Panti Sosial Tresna Werdha berdasarkan hasil survey yaitu gedung kantor, gedung aula, hunian perawatan khusus, gedung keterampilan, gedung kolam renang,klinik, perpustakaan, gedung service dan masjid.

Perancangan Panti Sosial Tresna Werdha berada pada lahan sekitar pantai yang sudah mengalami pengerasan tanah. Dasar pertimbangan untuk penentuan sistem struktur pada pembangunan Panti Sosial Tresna Werdha : (1) Kekuatan sistem struktur bangunan, (2) Bangunan mempunyai ketinggian $\pm 12 \mathrm{~m}$, (3)Konstruksi bangunan, ukuran komponen bangunan, cara pengerjaannya dan lain-lain, (4) Nilai estetika konstruksi bangunan, (5) Kemudahan penyelesaian masalah-masalah konstruksi bangunan.

Struktur bawah bangunan hunian lansia menggunakan pondasi poer, hal ini karena disesuaiankan dengan kondisi tapak (Marwati, Wasilah 2018), struktur tengah menggunakan beton bertulang, sedangkan struktur atas menggunakan kuda-kuda kayu (Gambar. 5), sedangkan struktur 
bawah bangunan Penunjang menggunakan pondasi garis, struktur tengah menggunakan beton bertulang, sedangkan struktur atas menggunakan kuda-kuda kayu (Gambar . 6)

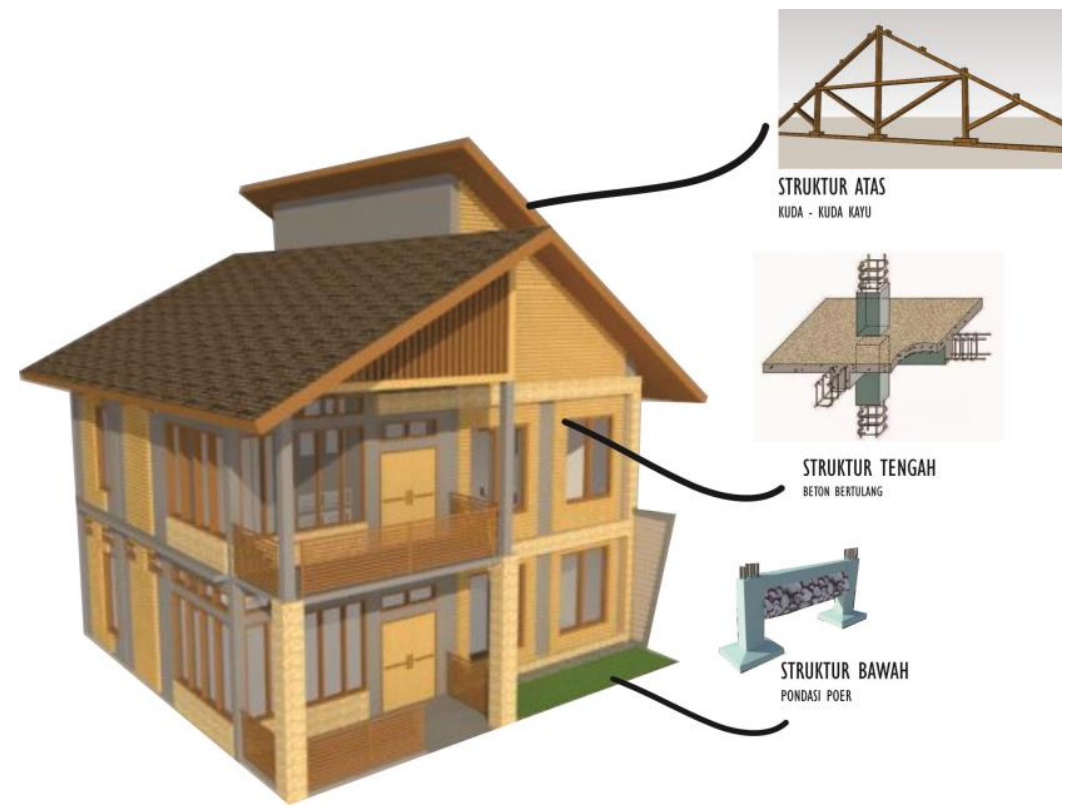

Gambar 5. Struktur Hunian Lansia Sumber: Hasil Dsain, 2018

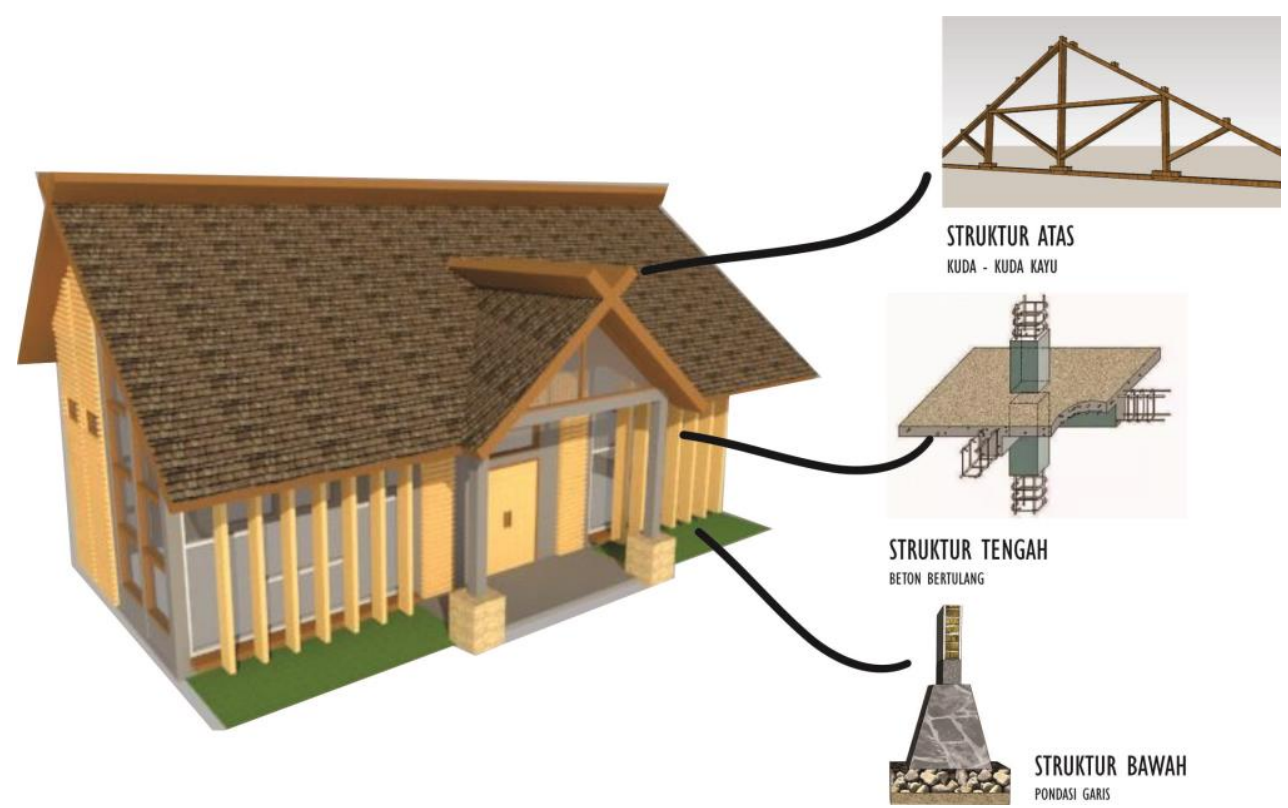

Gambar 6. Struktur Bangunan Penunjang Sumber: Hasil Dsain, 2018

\section{Sarana Penunjang}

Sarana dan prasarana pada Panti Sosial Tresna Werdha terdiri dari; taman lansia berfungsi sebagai area berkumpul dan bersantai, kebun lansia, dan lapangan olahrga. Untuk fasilitas penunjang pada Panti Sosial Tresna Werdha secara visual dapat dilihat pada (Gambar 7) berikut : 

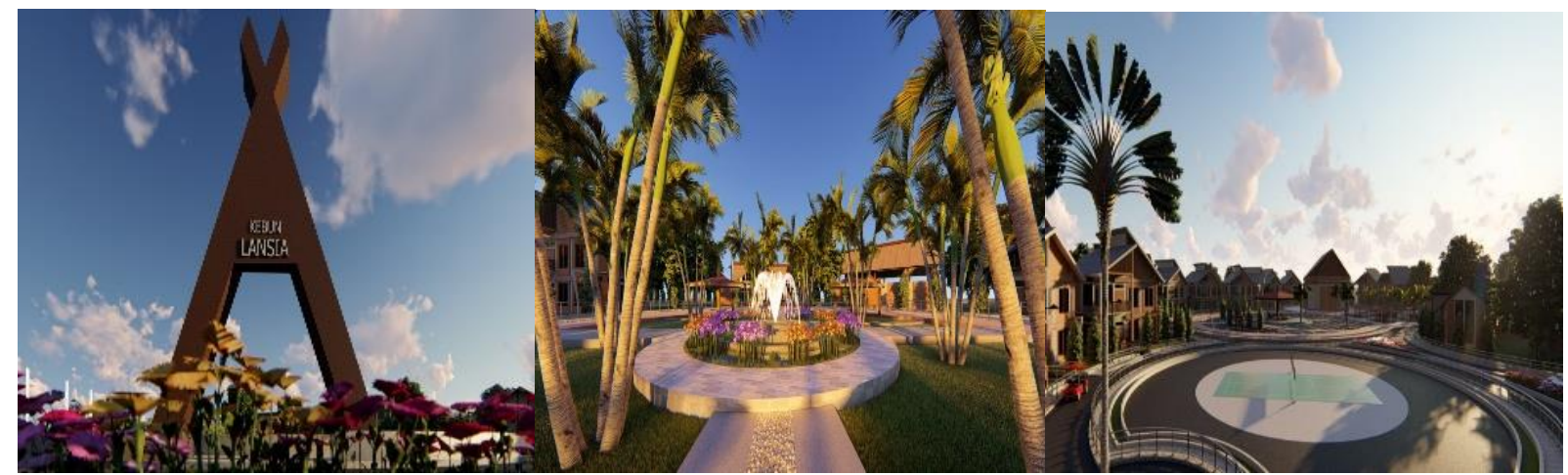

Gambar 7. Sarana Penunjang

Sumber: Hasil Desain, 2018

Sedangkan sarana penunjang pada hunian lansia terdiri dari star lift untuk akses lansia menuju ke lantai 2 (Gambar. 8f), penggunan nursing call disetiap kamar lansia digunakan dalam keadaan darurat yang di letakkan dekat dengan tempat tidur lansia (Gambar.8c), menyediakan handrail disetiap area yang dilalui oleh lansia (Gambar.8d dan 8e), speaker yang diletakkan pada ruang berkumpul lansia (Gambar. 8b) , dan menyediakan area berkumpul untuk lansia seperi ruang keluarga dan teras pada hunian dilengkapi dengan kursi yang nyaman digunakan untuk lansia (Gambar.8a dan 8b). Visualisasi fasilitas penunjang pada tapak hunian lansia dibuat dalam bentuk yang simpel, saling menunjang dan kompak, serta masih dalam jangkauan yang nyaman untuk lansia (Gambar.9 dan Gambar. 10)

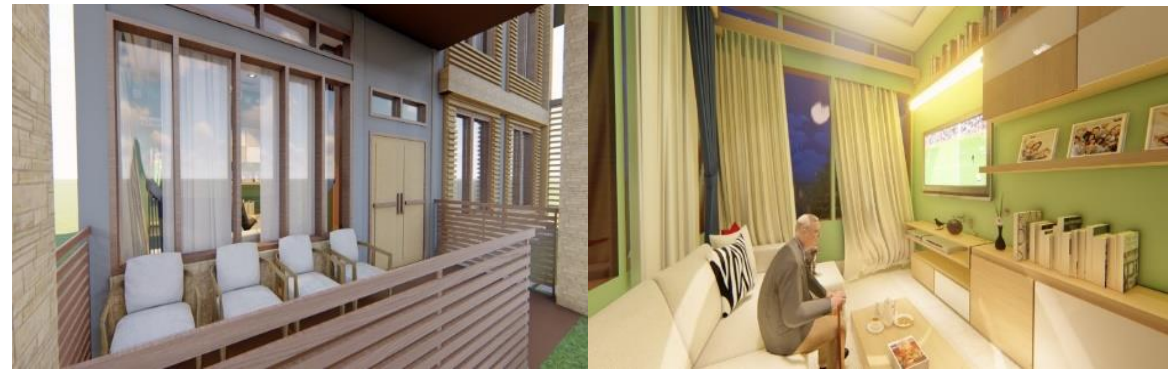

(a)

(b)

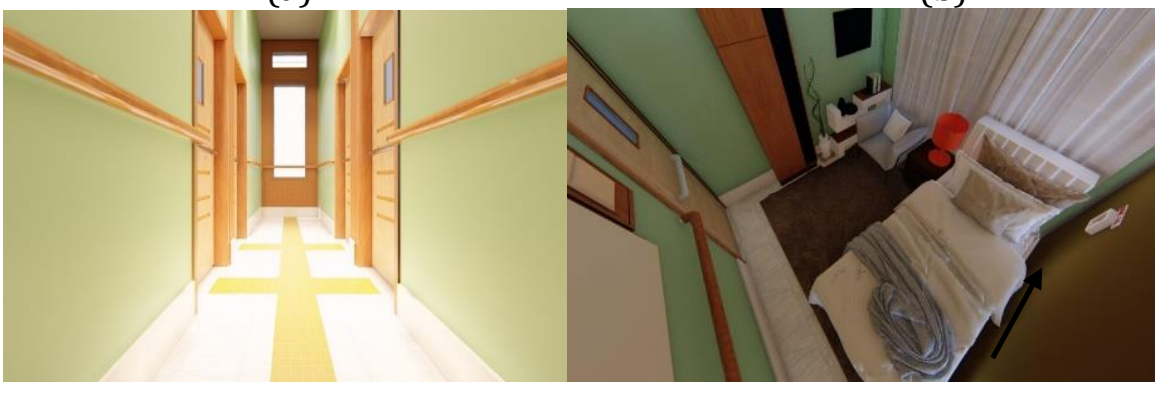

(c)

(d)

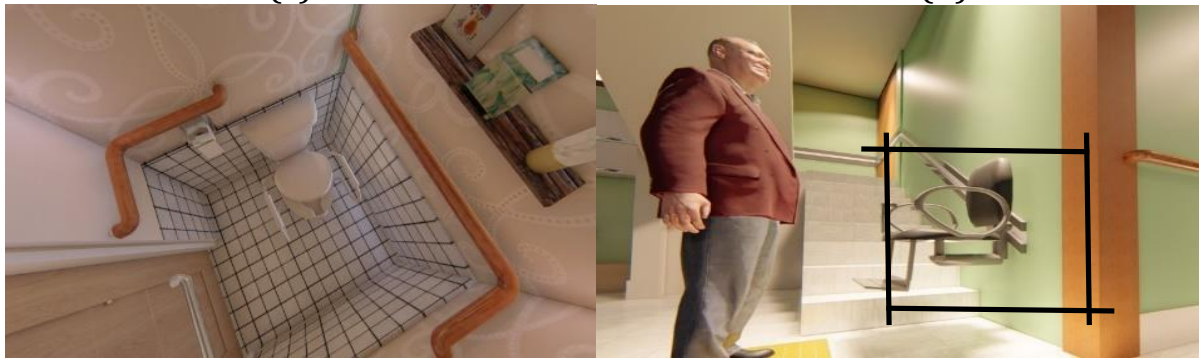

(e)

(f)

Gambar 8. Sarana Penunjang pada Hunian Lansia Sumber ; Hasil Desain, 2018 


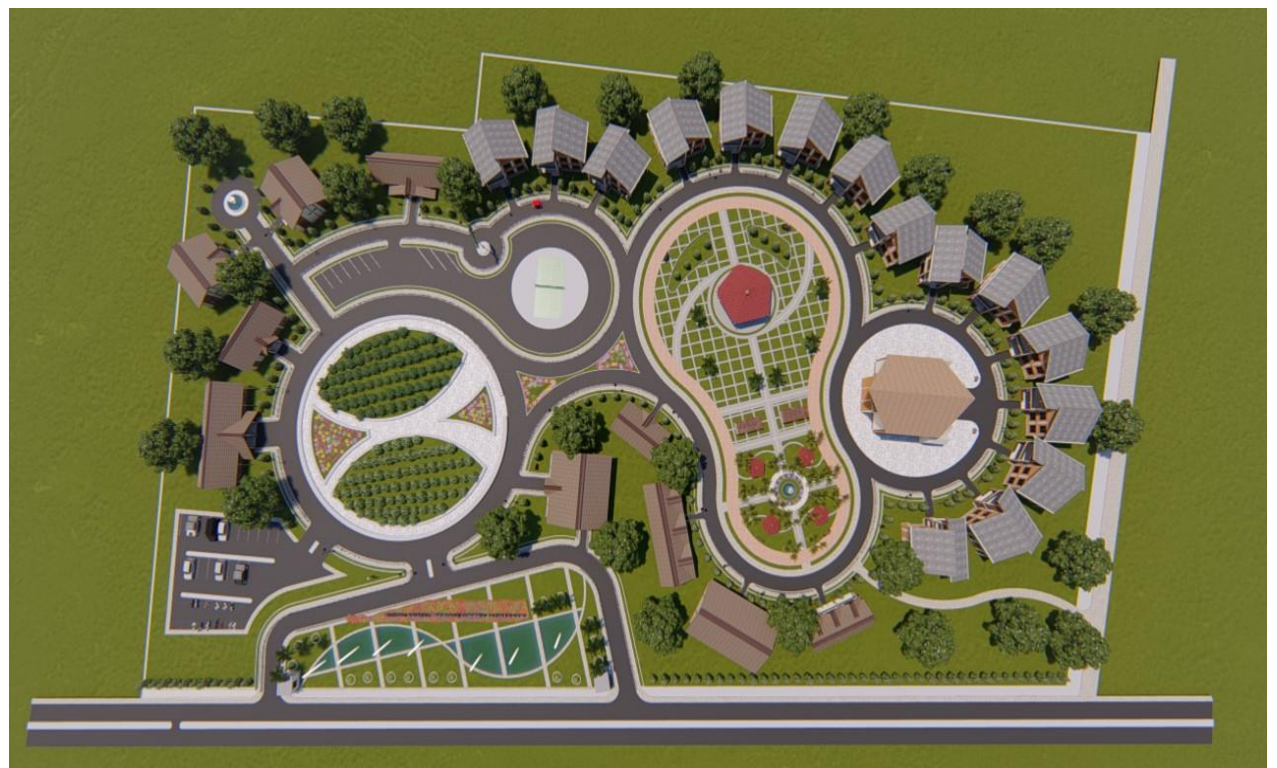

Gambar 9. Desain Tapak

Sumber: Hasil Desain, 2018

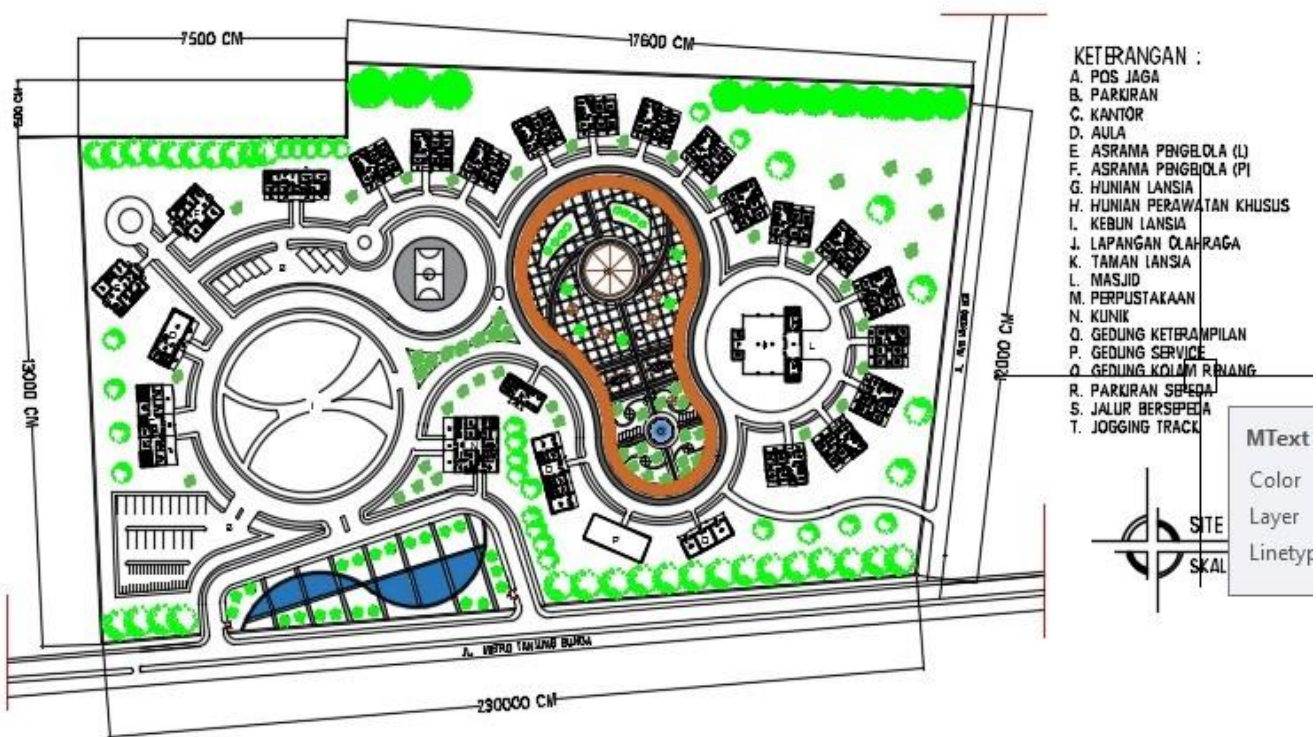

Gambar 10. Bangunan dan Fasilitas pada Kawasan Sumber: Hasil Dsain, 2018

\section{KESIMPULAN}

Pembangunan Panti Sosial Tresna Werdha memiliki fungsi beragam dan desain perletakan bangunan dibuat menyebar, ditata sesuai dengan fungsi tiap unit bangunan dan pola aktifivitas sehari-hari penghuninya. Desain pada tapak dibagi menjadi empat zona yaitu zona public, zona semi publik, zona privat dan service. Hal-hal yang harus diperhatikan ketika mendesain Panti Sosial Tresna Werdha yaitu keselamatan dan keamanan lansia, pola aktivitas dan rutinitas lansia, aksebilitas, kebutuhan lansia, dan semua hal kecil yang mungkin akan berdampak buruk pada kehidupan lansia yang akan tinggal di Panti Sosial Tresna Werdha. 
Dalam perancangan Panti Sosial Tresna Werdha dengan konsep perilaku menghasilkan desain dengan fungsi utama yaitu hunian yang terdapat ruang kamar tidur lansia, area berkumpul para lansia (ruang keluarga), ruang makan, kamar mandi, wc, dan teras untuk area bersantai. Sedangkan bangunan dengan fungsi penunjang terdiri dari gedung kantor, aula, asrama pengelola, gedung perawatan khusus lansia, Masjid, gedung service, gedung kolam renang, gedung keterampilan, perpustakaan dan klinik. Pola hubungan antara bagian gedung tersebut didesain dengan menyesuaikan kebutuhan penghuni utamanya yakni lansia.

\section{DAFTAR REFERENSI}

Angelina, Agustina, Widyani Ika, Gatot, Suharjanto. 2015. Pendekatan Arsitektur Perilaku Pada Panti Werdha Di. Binus University. Jakarta.

Badan Pusat Statistik Sulawesi Selatan. n.d. Statistik Penduduk Lanjut Usia.

Dinas Sosial Provinsi Sulawesi Selatan pada tahun 2017. n.d.

Evian, Devi. 2016. "Pola Penataan Ruang Panti Jompo Berdasrkan Aktivitas Dan Perilaku Penghuninya." Arteks 1 (1).

Marwati, Wasilah, Ulfa Idin Hamja. 2018. "Desain Permukiman Nelayan Pantai Merpati Di Kabupaten Bulukumba.” NATURE: National Academic Journal of Architecture 5 (5): 23-30.

Peraturan Daerah kota Makassar No. 4 Tahun 2015. n.d.

Peraturan Daerah Kota Makassar Nomor 31 tahun 2004 pasal 15e. n.d.

Rencana Tata Ruang Wilayah (RTRW) Kota Makassar tahun 2015-2034 yaitu Sub Pelayanan Kota, Pasal 20 ayat 2 . n.d.

UUD 1945, pasal 28H, ayat 1. n.d. 